\title{
Study of Oil Migration Processes in Meadow Soils
}

\author{
Yuriy Sivkov ${ }^{1}$, Artur Nikiforov ${ }^{*}$, Nikolay Fefilov ${ }^{2}$ \\ 1 Department of Technospheric safety, Tyumen Industrial University, Tyumen, Russia \\ 2 Environmental Research Laboratory, Tyumen State University, Tyumen, Russia \\ * Corresponding e-mail: arhont607@gmail.com
}

\begin{abstract}
The paper presents the results of field and laboratory studies aimed at studying the processes of oil transformation in the soil under the influence of natural biological processes during a two-year period on artificially created old spills. The soil of the study area was characterized as meadow. The high toxic effect of oil was confirmed, which was expressed in the complete extinction of soil flora and fauna. Despite the low oil content in the soil (less than $5 \%$ ), soil self-purification processes were not observed. Moreover, the high sorption properties of the soil, the violation of the water regime and the lack of aeration led to the "conservation" of oil and significantly slowed down the natural processes of its biodegradation. This was confirmed by a slight change in the content of oil products a year after the start of the experiment, as well as the presence of free oil in the pore space of the studied soil.
\end{abstract}

Keywords: soil contamination, migration of pollutants, total petroleum hydrocarbon, remediation, ecology

\section{INTRODUCTION}

Soil contamination with crude oil and petroleum products is the subject of attention of many scientists in the world [Anderson, 1980; Bondarenko, 2008; Solntseva, 1985, 1996; Lova Sari, et al. 2018]. Abosede [2013] investigated the effect of oil on the physical properties of the soil. Okonokhua et al. [2007] were engaged in study of the effect of spent engine oil (SEO) on soil properties and growth of maize in Nigeria. Natural decomposition of polycyclic hydrocarbons and other high-molecular compounds in soils lasts for many years, this opinion is confirmed by Pikovsky [1985] and Solntseva et al. [1985]. Kalachnikov [1987] identifies three stages of the soil self-purification process: the first stage is the leaching, weathering and distribution of petroleum hydrocarbons in the soil profile; the second stage is reduced to a biological transformation methanonaphthalene and aromatic hydrocarbons; and the third stage is the degradation of polycyclic aromatics.

The study of oil transformation processes under different environmental conditions will contribute to the formation and expansion of knowledge in the field of oil pollution destruction.

\section{MATERIALS AND METHODS}

The research was conducted to study the processes of oil transformation in the soil, under the influence of natural processes, during a two-year period on artificially created old spills. Reference areas were laid in $30 \mathrm{~km}$ South of Tyumen, Russian Federation. The nearest settlement is the Chervishevo village.

Two sections S1 and S2 with dimensions of $0.12 \times 0.12 \mathrm{~m}$ were allocated for the experiment, shown in Figure 1. Preliminary preparation was carried out at the sites, which consisted in determining the boundaries of the sites and removing the above-ground part of the vegetation cover.

As a result of the study of morphological characteristics, the soil of the study area was characterized as meadow leached medium-thick low-humus medium-loamy. Soil-forming rocks are loam and clay. 


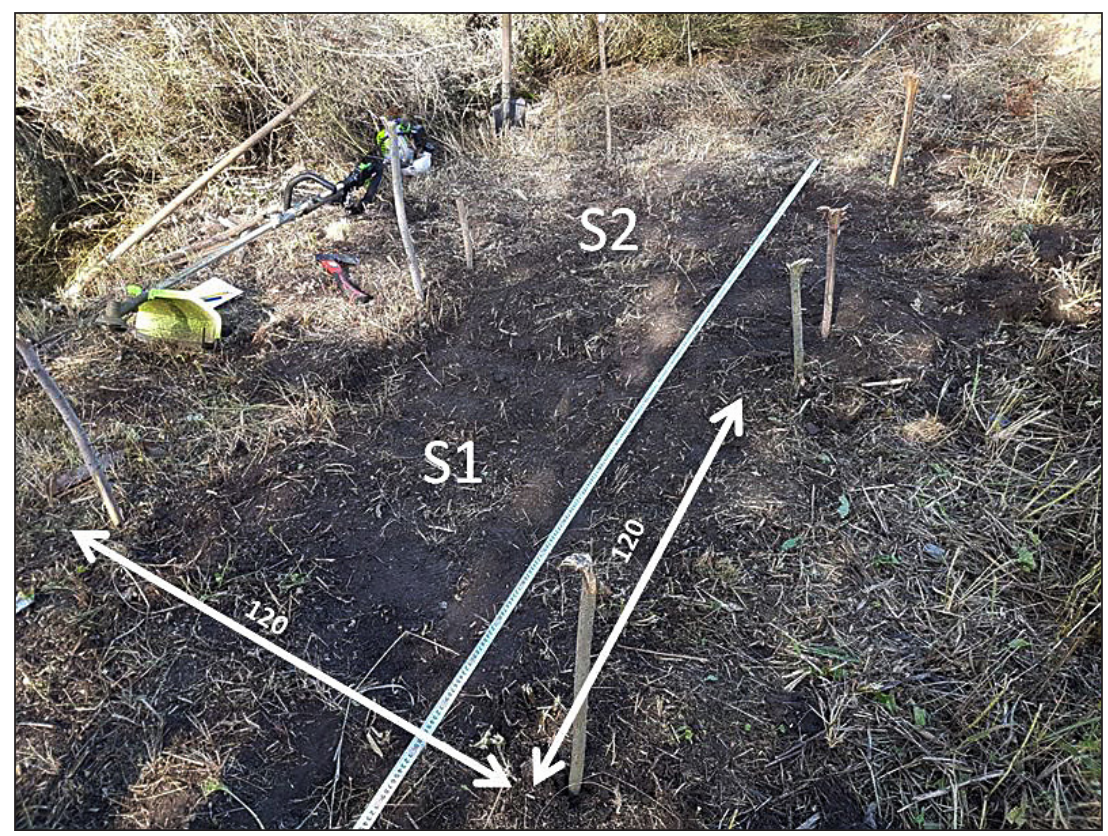

Figure 1. The definition of the boundaries and size of reference areas

- Horizon A0 with a capacity of 0-0.02 m has an organogenic composition and mainly consists of plant roots.

- Horizon A1 (0.02-0.33 m) has a black color, lumpy structure, dense, mechanical composition - medium-loamy.

- Horizon AB (0.33-0.50 m) has a brownish-dark gray color, lumpy structure, compacted, mechanical composition-heavy loam.

- Horizon B1 (0.50-0.73 m) has a whitish-brown color with ochre spots of iron, lumpy structure, wet, the mechanical composition - the average loam with a single filling of humus.

- Horizon B2 (0.73-1.10 m) has a whitish-brown color with ochre spots of iron, lumpy structure, raw, in mechanical composition - light loam.

- Horizon C (1.10-1.50 m) has a brownish-light gray color, lumpy structure with inclusions of iron and calcium carbonate, it has a water, the mechanical composition-clay.

On the reference areas with an area of $1.44 \mathrm{~m}^{2}$ each, spills in volumes of 20 (S1) and 10 (S2) liters of oil taken from the Shaim-Tyumen oil trunk pipeline were simulated. After complete oil seepage, the areas were fenced.

The selection of soil samples using soil drill Kaczynski was carried out on the reference areas for two years for laboratory studies. Soil samples were taken from sites S1 and S2, with a control sample on the unpolluted site. Samples were taken from two horizons: $0.0-0.2$ and $0.2-0.4 \mathrm{~m}$.
The analysis of oil products content was carried out by IR spectrometry. From a soil sample weighing $0.5-5 \mathrm{~g}$ (depending on the expected content of petroleum products: $5 \mathrm{~g}-<500 \mathrm{mg} / \mathrm{kg}$; $1 \mathrm{~g}-(500-2000) \mathrm{mg} / \mathrm{kg} ; 0.5 \mathrm{~g}->2000 \mathrm{mg} / \mathrm{kg}$ ) oil products are extracted by triple extraction, portions of $10 \mathrm{~cm}^{3}$ carbon tetrachloride for 1 hour, then, chromatographically (on a column with aluminum oxide of the II degree of Brockman activity), petroleum products are separated from the accompanying organic compounds of other classes and the content of petroleum products is quantitatively determined by the absorption intensity in the IR-region of the spectrum on the analyzer of the content of petroleum products in the AH-2 carbon tetrachloride. Then you need to calculate the mass fraction of petroleum products in $\mathrm{mg} / \mathrm{kg}$ in terms of air-dry soil.

\section{DISCUSSION}

To predict the degree of impact of possible accidental oil spills on the components of the natural environment, and especially on the soil, which is an intermediate medium between the ground and water, it is necessary to know the mechanisms of oil filtration in it. Soil contamination will inevitably lead to contamination of adjacent media.

The work was carried out modeling of old oil spills and assessment of their environmental consequences. 
At the beginning of the experiment, the oppression of vegetation was visually noted, a persistent characteristic oil smell appeared, the color of the soil changed. These changes persisted for several days due to intensive evaporation of light fraction of hydrocarbons. Seven days after the start of the experiment, soil samples were taken for laboratory studies, and photofixation was performed. Figure 2 shows a photo of an oil spill from 7 days ago.

At the site of the spill, there is complete destruction of all soil flora and fauna; there is a characteristic oil smell and color; when sampling, the storm remains a clear oily spot, up to a depth of $0.40 \mathrm{~m}$. This fact indicates a high concentration of oil in the soil. The results of laboratory studies of selected soil samples are presented in Table 1.

Laboratory data show approximately the same content of petroleum products in the areas of S1 and S2, while the volume of spilled oil differs by 2 times (20 and 10 liters). These results can be explained by the sorption properties of this type

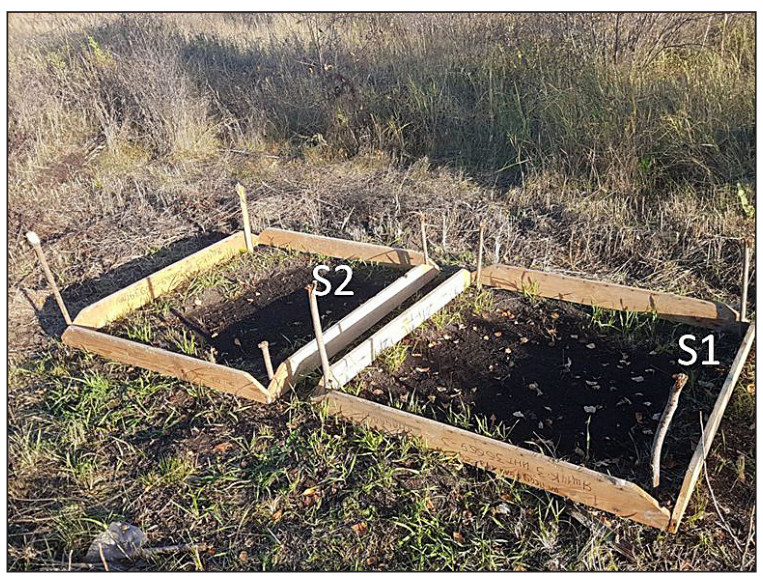

Figure 2. Appearance of simulated oil spills at reference sites ( 7 days after the start of the experiment)
Table 1. Oil content in the soil at the beginning of the experiment, $\mathrm{mg} / \mathrm{kg}$

\begin{tabular}{|c|c|c|}
\hline Horizon, $\mathrm{m}$ & Site S1 & Site S2 \\
\hline $0.0-0.20$ & 39129 & 37652 \\
\hline $0.20-0.40$ & 20910 & 18279 \\
\hline
\end{tabular}

Table 2. Results of the analysis of the oil content in the soil a year after the start of the experiment, $\mathrm{mg} / \mathrm{kg}$

\begin{tabular}{|c|c|c|}
\hline Horizon, $\mathrm{m}$ & Site S1 & Site S2 \\
\hline $0.0-0.20$ & 37658 & 34932 \\
\hline $0.20-0.40$ & 18345 & 15745 \\
\hline
\end{tabular}

of soil, and, apparently, they allow us to judge the migration processes occurring during oil spills. In this case, it can be concluded that the rate of horizontal migration of oil is much higher than the vertical, since the area of the spill spot on the site $\mathrm{S} 1$ is greater than on the site $\mathrm{S} 2$.

The obtained values of oil products concentration in the selected samples correspond to the average pollution level $(600-40000 \mathrm{mg} / \mathrm{kg})$ according to the Pikovsky classification (2003).

The next stage of observations took place a year after the first studies. At the site of the spill site $\mathrm{S} 1$ is still no vegetation (Figure 4A), which suggests that the processes of self-restoration of the soil are depressed in the long term. There is a persistent smell of hydrocarbons, the soil has clear boundaries of oil.

On the site S2 (Figure 4b) there are processes of self-restoration of the soil, which consist in the gradual settlement of plants at the site of oil spill. At both sites outside the boundaries of spills no evidence of suppression of vital activity of plants, which indicates the absence of processes the horizontal migration of oil from the inception of the spill.
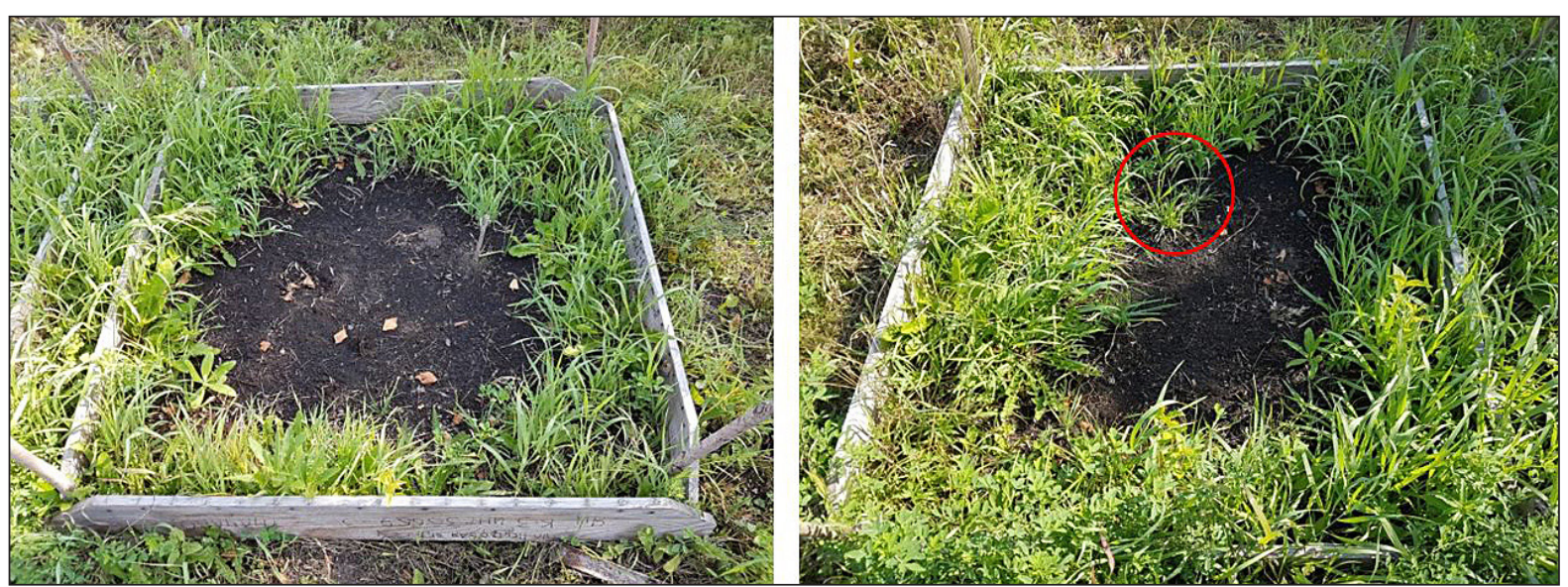

Figure 3. Old model of oil spill at the reference sites (a year after the beginning of the experiment) 


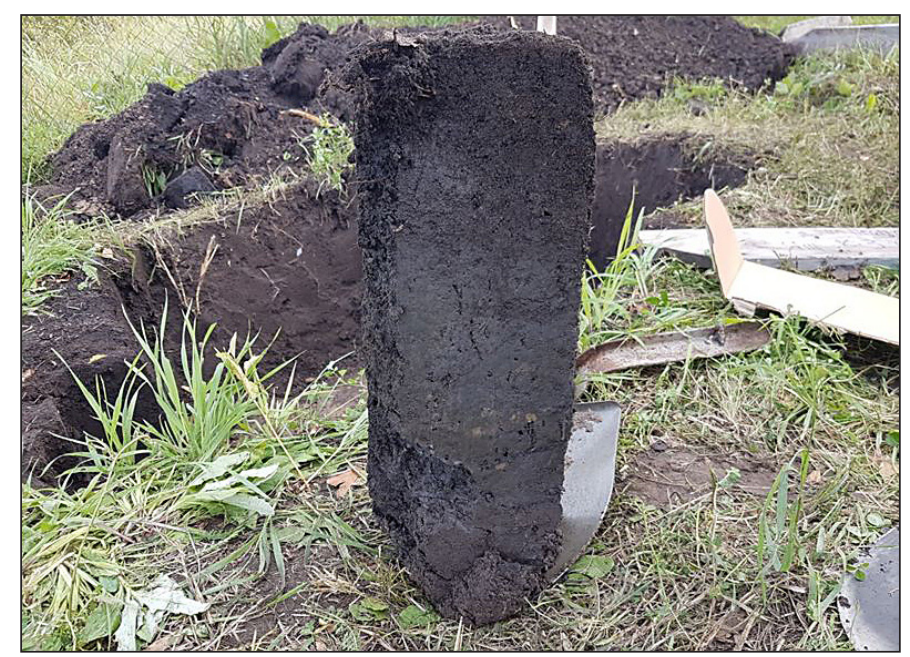

Figure 4. Section of oil-contaminated soil

In the second year, soil samples were taken from these sites and similar horizons. The results of the analysis of soil samples (Table 2) show a slight decrease in the concentration of petroleum products (from $4 \%$ to $7 \%$ ) compared to the first year.

To study the depth of oil seepage, a section of the soil profile was made, which showed the presence of "preserved" oil in free form in large pores, which is explained by the sorption properties of this type of soil (Figure 4).

\section{CONCLUSIONS}

As a result of the conducted field and laboratory studies, the high toxic effect of oil was confirmed, which was expressed in the complete extinction of soil flora and fauna. Despite the low oil content in the soil (less than 5\%), soil self-purification processes were not observed. Moreover, the high sorption properties of the soil, the violation of the water regime and the lack of aeration led to the "conservation" of oil and significantly slowed down the natural processes of biodegradation of the pollutant. This was confirmed by a slight decrease in the content of petroleum products (4-7\%) a year after the spill, as well as the presence of free oil in the pores of oil-contaminated soil. The results allow to draw conclusions about the need for timely restoration work, which will help to reduce the environmental consequences of oil spills.

\section{REFERENCES}

1. Abosede E.E. 2013. Effect of crude oil pollution on some soil physical properties. IOSR Journal of Agriculture and Veterinary Science, 6(3), (Nov.-Dec.), 14-17.
2. Okonokhua B.O., Ikhajiagbe B., Anoliefo G.O., Emede T.O. 2007. The Effects of spent engine oil on soil properties and growth of maize (Zea mays L.). J. Appl. Sci. Environ. Manage. September, 11(3). 147-152.

3. Pikovsky Yu. I. 1985. Experimental study of the transformation of oil in soil. In: Yu. I. Pikovsky, I.G. Kalachnikova, A.I. Obloblina, A.A. Oborin (Eds.) Migration of pollutants in soils and adjacent environments,

4. Solntseva N.P. 1985. Problems of soil contamination with oil and oil products: Geochemistry, ecology, reclamation. In: N.P. Solntseva, Yu. I., Pikovsky, E.M. Nikiforova, A.A. Oborin (Eds.) Dokl. Symposium. VII delegate. Congress of GP 1985., Tashkent, Mehnat, pp. 246-254.

5. Solntseva N.P., Guseva O.A., Goryachkin S.V. 1996. Modeling of oil and oil products migration processes in tundra soils. Vestnik MSU. Ser. 17. Soil Science, No. 2. pp. 23-28.

6. Kalachnikov I.G., 1987. The influence of oil pollution on the ecology of soils and soil microorganisms. In: I.G. Kalachnikov, Ecology and population genetics of microorganisms. Sverdlovsk, pp. 24-29.

7. Pikovsky Yu. I. 2003. The Problem of diagnostics and standardization of soil pollution with oil and oil products. In: Yu.I. Pikovsky, A.N. Gennadiev, S.S. Chernyavskiy, G.N. Saharov (Eds.), Soil Science, No. 9. 1132-1140.

8. Anderson R.K. 1980. Environmental effects of oil pollution. In: R.K. Anderson, A.H. Mukatanov, T.F. Boyko, Ecology, No. 6, 21-25.

9. Bondarenko A.N. 2008. Assessment of oil pollution of soils in arid areas (on the example of the Astrakhan Region). Dis. Cand. Geogr. of Sciences, Astrakhan, pp. 24.

10. Lova Sari G., Trihadiningrum Y., Ni'matuzahroh 2018. Petroleum hydrocarbon pollution in soil and surface water by public oil fields in Wonocolo Subdistrict, Indonesia. Journal of Ecological Engineering, 19(2), 184-193. 